\title{
Effects of Pulmonary Oxygen Injury on Airway Content of Surfactant-Associated Protein A
}

\author{
LAWRENCE M. NOGEE AND JONATHAN R. WISPE
}

Department of Pediatrics, University of Cincinnati, Cincinnati, Ohio 45267-0541

\begin{abstract}
The use of therapeutic hyperoxia has greatly improved the survival of infants born prematurely. However, high concentrations of oxygen cause pulmonary injury, leading to decreased pulmonary compliance and decreased oxygen diffusion. This injury can result in chronic pulmonary insufficiency. It has been hypothesized that the adverse effects of hyperoxia are mediated, in part, through changes in the pulmonary surfactant system. We investigated the effects of hyperoxia on surfactant-associated protein A (SP-A), the abundant surfactant-specific glycoprotein. Adult male rats were exposed to $85 \%$ oxygen for $72 \mathrm{~h}$. Total lung volume and pulmonary compliance were measured, and alveolar surfactant material recovered by lavage. Hyperoxia decreased total lung capacity, and altered inflation and deflation hysteresis patterns. Disaturated phosphatidylcholine and SP-A content were significantly increased in alveolar surfactant material isolated from oxygen-treated rats. SP-A content was also significantly increased in lung tissue from oxygen-treated rats. The SP-A in the lavage of oxygen-treated rats appeared to be intact protein as no proteolytic fragments were detected and the SP-A migrated identically to that recovered from room air animals when analyzed by two-dimensional isoelectric focusing. We conclude that the decreased pulmonary compliance associated with pulmonary oxygen injury is not due to quantitative decreases in two major surfactant components, disaturated phosphatidylcholine and SP-A. (Pediatr Res 24: 568-573, 1988)
\end{abstract}

\section{Abbreviations}

RDS, respiratory distress syndrome

SP-A, surfactant-associated protein $A\left(M_{\mathrm{r}} 26,000-36,000\right)$

DSPC, disaturated phosphatidylcholine

SDS-PAGE, sodium dodecyl sulfate polyacrylamide gel electrophoresis

ELISA, enzyme-linked immunosorbent assay

RDS is a major cause of morbidity and mortality in premature infants. The primary cause of RDS is insufficient pulmonary surfactant, a complex mixture of lipids and proteins necessary for reducing surface tension and preventing end expiratory collapse of alveoli. Infants with RDS have decreased pulmonary compliance, microatelectasis, and require increased concentrations of inspired oxygen. Although supplemental oxygen benefits

Received February 1, 1988; accepted June 29, 1988.

Correspondence Jonathan R. Wispe, M.D., University of Cincinnati College of Medicine, Department of Pediatrics, Div. of Neonatology, 231 Bethesda Avenue, Cincinnati, OH 35267-0541.

Supported in part through an NIH Training grant HD 07200 (L.M.N.), through a grant from the American Lung Association (J.R.W.), and by the Children's Hospital Research Foundation. these infants, the high levels of oxygen necessary to maintain life are injurious to pulmonary tissue. Exposure to inspired hyperoxia causes pulmonary edema, alveolar and interstitial hemorrhage, and endothelial and epithelial cell necrosis $(1,2)$. Pulmonary oxygen injury is associated with decreased lung compliance and impaired function of isolated surfactant material (3-6). Oxygen injury may, therefore, further compromise respiratory function in infants with RDS.

Pulmonary surfactant is composed of approximately $90 \%$ lipid and $10 \%$ protein. The major surfactant phospholipid is phosphatidylcholine, of which approximately $80 \%$ is DSPC. The effects of hyperoxia on surfactant phospholipids have been examined by a number of investigators. Results are conflicting depending on animal species and age, and on level and duration of inspired oxygen treatment $(3,4,6-14)$. Ward and Roberts (14) demonstrated decreased airway phospholipids and decreased DSPC synthesis in lung slices from newborn rabbits exposed to $95 \%$ oxygen for $48 \mathrm{~h}$. Beckman and Weiss (13) demonstrated decreased lavage DSPC in adult rats exposed to $100 \%$ oxygen for 60-66 h. In contrast, Young et al. (11) found increased lavage and lung DSPC content in adult rats exposed to $85 \%$ oxygen for 7 days.

Whereas the lipid components are critically important for surfactant function, recent studies indicate that the surfactantassociated proteins are necessary for full biophysical function of the surfactant complex, and may regulate secretion and reuptake of surfactant phospholipids (15-19). The most abundant nonserum protein in surfactant is a glycoprotein with a mol. wt. between 26,000-36,000 Da, herein called SP-A. This protein is synthesized and secreted primarily by pulmonary type II epithelial cells $(20-23)$.

The effects of hyperoxia on specific surfactant-associated proteins have not been previously reported. We hypothesized that airway content of SP-A would be altered by pulmonary oxygen injury. In our study we investigated the effects of hyperoxia on the content of SP-A, total protein, and DSPC in alveolar lavage fluid, and on total lung SP-A content from adult rats.

\section{MATERIALS AND METHODS}

Animals. Adult male Sprague Dawley rats (weight 300-390 g) were exposed to hyperoxia $\left(0.85 \mathrm{FIO}_{2}\right)$ or room air for $72 \mathrm{~h}$. The oxygen-treated rats were housed in 3 cubic foot Lucite chambers. Each chamber received oxygen at 6 liter/min and oxygen concentration was measured continuously with an oxygen analyzer (Ventronics, Temecula, CA). During the exposure period, $\mathrm{CO}_{2}$ concentration in the chamber was less than $1 \%$. Animals in room air were maintained in open cages. Animals were allowed food and water ad libitum.

Pressure volume analysis and lavage collection. After the $72-\mathrm{h}$ exposure period, animals received a lethal intraperitoneal injection of pentobarbital $(50 \mathrm{mg} / \mathrm{kg})$ and were placed in $100 \%$ oxygen for $10 \mathrm{~min}$ to metabolically degas the lungs. Leaving the thorax undisturbed, the tracheas were cannulated and connected to a 
U-tube water manometer. The lungs were slowly inflated to 30 $\mathrm{cm} \mathrm{H}_{2} \mathrm{O}$ pressure and this volume recorded as $\mathrm{V} 30$. This pressure was maintained for $5 \mathrm{~min}$ before deflation. A drop in pressure of more than $5 \mathrm{~cm} \mathrm{H}_{2} \mathrm{O}$ during this period was considered to result from an air leak, and the animal was excluded from analysis. After a 5-min equilibration period, the lungs were incrementally inflated and deflated, and pressure recorded at each volume. Volumes were corrected for air compression in the system and expressed as percent of volume at $30 \mathrm{~cm} \mathrm{H} \mathrm{H}_{2} \mathrm{O}$ pressure. Calculation of pressure:volume as percent V30 allows analysis of compliance changes irrespective of alterations in maximum lung compliance. After compliance measurements, the lungs were lavaged 10 times with cold buffer $\left(4^{\circ} \mathrm{C}\right)$ containing $154 \mathrm{mM} \mathrm{NaCl}, 20 \mathrm{mM}$ Tris- $\mathrm{HCl}(\mathrm{pH} \mathrm{7.4)}$, and $3 \mathrm{mM}$ EDTA using a volume equal to $80 \%$ of V30. Fresh buffer was used for each lavage. Total recovered lavage fluid from each animal had to be at least $85 \%$ of volume instilled to qualify for inclusion in the analysis. Pulmonary lavage was processed by centrifugation at $500 \times \mathrm{g}$ for $10 \mathrm{~min}$ at $4^{\circ} \mathrm{C}$ to remove cell debris. The supernatant was centrifuged at $12,500 \times g$ for $30 \mathrm{~min}$ and the resulting surfactant pellet was resuspended in $1 \mathrm{ml}$ of lavage buffer and frozen at $-30^{\circ} \mathrm{C}$ before analysis. Aliquots of unprocessed lavage, low and high speed supernatants were also frozen for analysis. SP-A was measured in each fraction from all animals. To compare changes in SP-A with changes in surfactant lipids, DSPC was measured in the surfactant pellets. In a separate group of animals (weight $225-410 \mathrm{~g}$ ), the lungs were removed immediately after lavage, and a $10 \%$ (wt/vol) homogenate made using a Tekmar Tissuemizer, in buffer containing $50 \mathrm{mM}$ Tris$\mathrm{HCl}, \mathrm{pH} 7.4,10 \mathrm{mM}$ EDTA, 0.1\% Nonidet P-40, 1 mM PMSF. SP-A concentration was measured in the lung homogenate by ELISA assay, and total lung SP-A content calculated as the product of SP-A concentration and homogenate volume, and normalized to body weight.

Measurement of SP-A. SP-A ELISA. Rat SP-A was measured by a sensitive capture ELISA following the methods of Katyal and Singh (24) as modified by McMahan et al. (25). Microtiter plates (Falcon Inc., Oxnard, CA) were coated with a 1:200 dilution of the rabbit anti-rat surfactant IgG antibody in $0.1 \mathrm{M}$ $\mathrm{NaHCO}_{3}$ overnight at $4^{\circ} \mathrm{C}$. Plates were washed four times with $10 \mathrm{mM}$ Tris- $\mathrm{HCl}(\mathrm{pH} 8.0), 0.5 \%$ Tween $20,0.01 \%$ merthiolate, and incubated for $10 \mathrm{~min}$. at room temperature with $100 \mu \mathrm{l} /$ well of $150 \mathrm{mM} \mathrm{NaCl}, 10 \mathrm{mM}$ Tris- $\mathrm{HCl}(\mathrm{pH} 7.4), 5 \mathrm{mg} / \mathrm{ml}$ bovine serum albumin. Buffer was removed and various dilutions of rat SP-A or lavage in $150 \mathrm{mM} \mathrm{NaCl}, 0.05 \mathrm{M} \mathrm{Na}_{2} \mathrm{H} \mathrm{PO}_{4}$ (pH 7.4), were added and incubated at $37^{\circ} \mathrm{C}$ for $2 \mathrm{~h}$. Plates were washed and incubated with $100 \mu \mathrm{l} /$ well of a 1:500 dilution of guinea pig anti-rat SP-A in $150 \mathrm{mM} \mathrm{NaCl}, 10 \mathrm{mM}$ Tris (pH 7.4), $5 \mathrm{mg} / \mathrm{ml}$ bovine serum albumin for $90 \mathrm{~min}$ at $37^{\circ} \mathrm{C}$. Plates were washed and horseradish peroxidase conjugated rabbit anti-guinea pig IgG (Miles Laboratories, Naperville, IL) was added for $1 \mathrm{~h}$ at $37^{\circ}$ C. Color was developed by the addition of $\mathrm{H}_{2} \mathrm{O}_{2}$ and $O$-phenylenediamine and absorbance at $490 \mathrm{~nm}$ measured (Dynatech Inc., Alexandria, VA). A standard curve was constructed from the absorbance of known amounts of SP-A and sample values calculated from dilutions that fell on a linear portion of the standard curve. Standard curves for the ELISA assay were sensitive to 10$150 \mathrm{ng} / \mathrm{ml}$ of protein with a correlation coefficient of $>0.95$ for all assays. All samples were measured in duplicate on two different occasions.

The SP-A standards were prepared by pelleting pooled lavage from adult rats at $10,000 \times g$ for $30 \mathrm{~min}$. The amount of SP-A in the standard was determined by measuring the total protein content by the method of Lowry as modified to enhance sensitivity in the presence of phospholipids (26). The fraction of SPA compared to total protein was then estimated by densitometry scanning of the standard analyzed on an SDS-PAGE after silver staining (27).

Preparation of Antibodies. Rat SP-A was purified from adult rat lung lavage using methods previously described by Ross et al. (28). This protein was $>95 \%$ pure as determined by SDSPAGE. Antisera against rat SP-A were prepared by repeated injections of approximately $200 \mu \mathrm{g}$ of the purified protein suspended in Freund's adjuvant into guinea pigs. An antibody against rat surfactant proteins was prepared in rabbits by repeated injections of $1 \mathrm{mg}$ of surfactant protein suspended in Freund's adjuvant into rabbits. Both antisera recognized the glycosylated and nonglycosylated forms of SP-A. Specificity of the guinea pig antiserum was assured by immunoblot analysis of crude rat alveolar lavage material. The immune globulin fraction of rabbit serum was prepared by precipitation with $30-50 \%$ ammonium sulfate; dissolved in a volume of $150 \mathrm{mM} \mathrm{NaCl}, 0.05 \mathrm{M} \mathrm{NaPO}_{4}$ ( $\mathrm{pH} 7.4$ ) equal to that of the original serum sample and dialyzed before use in the ELISA assay.

Gel electrophoresis and immunoblot analysis. SDS-PAGE was performed as described using the buffer of Laemmli (29). Twodimensional isoelectric focusing-SDS-PAGE was carried out using the buffer system of Garrison and Wagner (30). Proteins were electrophoretically transferred to nitrocellulose paper and identified by immunoblot analysis using nonfat dried milk to reduce background staining $(31,32)$.

DSPC measurement. DSPC was measured by extraction of lipids from the surfactant pellet, followed by reaction with osmium tetroxide and alumina chromatography (33).

Statistical analysis. Results are expressed as mean \pm 1 SD. Results were analyzed on an IBM PC-XT computer using a statistical software package (NCSS, Kaysville, UT). Comparisons between groups were made with a two-tailed $t$ test for unpaired observations, with the Bonferroni method for correction for multiple comparisons.

\section{RESULTS}

After $72 \mathrm{~h}$ in $85 \%$ oxygen, all rats were lethargic, refused food and water, and had variable degrees of respiratory distress with retractions and nasal flaring. One of $18(5.6 \%)$ oxygen treated rats died. Although the rats maintained in room air did not differ significantly in initial weight from oxygen exposed rats, rats exposed to oxygen lost weight during the study (Table 1).

Pressure-volume analysis. Lung capacity (V30) was decreased in oxygen exposed rats when compared to room air controls (Table 1). Because the volume of buffer used to lavage the rats depended on $\mathrm{V} 30$, the total lavage volume was also reduced in oxygen treated as compared to room air rats $(81 \pm 16$ versus 129 $\pm 14 \mathrm{ml}$ ). The hysteresis patterns differed between the two groups. The oxygen-treated rats required higher pressures to achieve a given lung volume during both inflation and deflation (Fig. 1).

Lavage content of surfactant proteins and phospholipids. Hyperoxia increased the SP-A content of all fractions of bronchoalveolar lavage (Fig. 2). SP-A content was increased 2- to 3-fold both in whole lavage and in the cell free, low speed supernatant; however, it was increased almost 5-fold in the surfactant pellets. A larger percentage of SP-A pelleted after centrifugation at 12,500 $\times g$ in the lavage from the oxygen-treated rats $(29 \pm 16 \%)$ than from the room air rats $(15 \pm 16 \%)$. The SP-A that did not pellet was accounted for in the high speed supernatant, and the percentage of total SP-A recovered in the surfactant pellets and in the high speed supernatant was similar in oxygen treated $(96 \pm$ $18 \%)$ and room air $(91 \pm 17 \%)$ rats. Exposure to $85 \%$ oxygen for $72 \mathrm{~h}$ also increased lung tissue SP-A content 2-fold; a similar increase to that seen in whole lavage (Fig. 3).

To assess if the increased amount of SP-A in the lavage fluid of oxygen exposed animals was intact protein or if oxygen exposure induced proteolysis of SP-A, aliquots of alveolar lavage containing approximately $1 \mu \mathrm{g}$ of SP-A from rats exposed to oxygen were lyophilized, resuspended in Laemmli buffer (29), and the proteins separated by SDS-PAGE and identified by immunoblot analysis. The results are shown in Fig. $4 A$. Proteolytic fragments of SP-A were not detected in these animals. Figure $4 B$ shows an immunoblot analysis of lavage material from an 
Table 1. Body wt and lung capacity of treated animals (mean \pm I SD)

\begin{tabular}{lccc}
\hline & Starting wt $(\mathrm{g})$ & Wt change $(\mathrm{g})$ & $\mathrm{V} 30(\mathrm{ml})$ \\
\hline Room air $(n=6)$ & $340 \pm 32$ & $+3 \pm 9$ & $17.4 \pm 2.0$ \\
$85 \%$ oxygen $(n=17)$ & $335 \pm 28$ & $-23 \pm 6^{*}$ & $11.2 \pm 1.5^{*}$ \\
\hline
\end{tabular}

$* p<0.05$; room air versus oxygen treated.

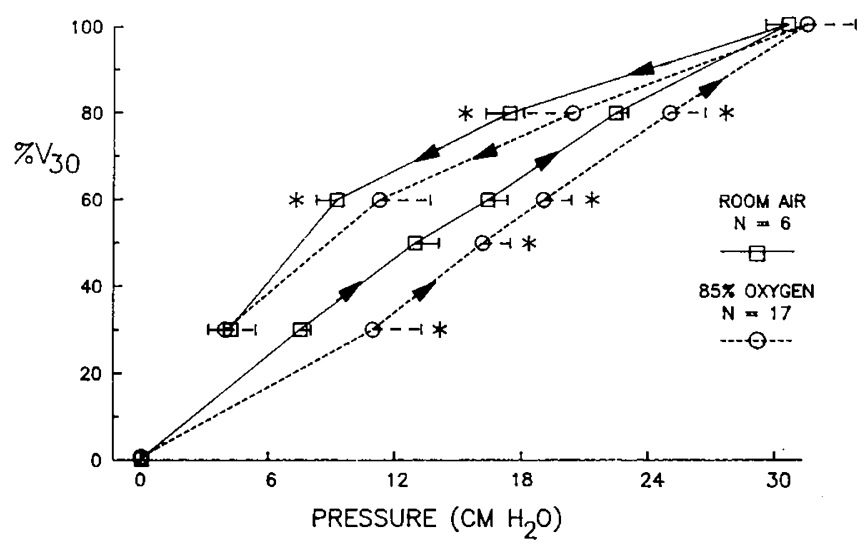

Fig. 1. Pressure-volume analysis. Rats were exposed to $85 \%$ oxygen or room air for $72 \mathrm{~h}$. Total lung capacity (V30) and pressure:volume measurements were made as described in "Materials and methods." Volumes are expressed as percent of V30. The mean pressure $\pm 1 \mathrm{SD}$ is shown for control (circles) and oxygen (squares) treated animals (at representative volumes) during inflation and deflation. Exposure to $85 \%$ oxygen for $72 \mathrm{~h}$ (dashed lines) decreased pulmonary compliance compared to rats maintained in room air (solid line). For any change in volume during both inflation and deflation, pressure was greater in oxygen-treated rats. An asterisk indicates a significant difference $(p<$ 0.05 ) between oxygen treated and room air animals.

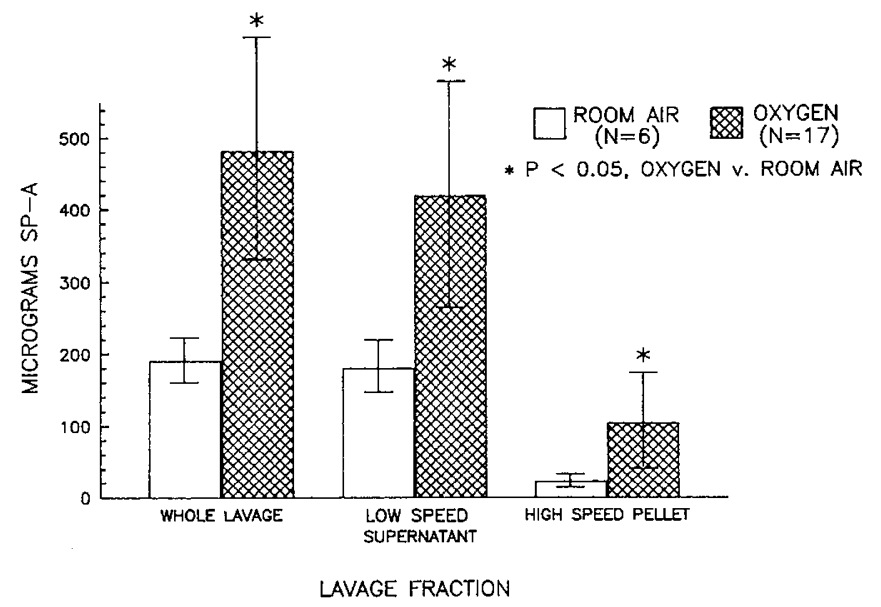

Fig. 2. SP-A content of lung lavage fractions. Rats were maintained in either $85 \%$ oxygen or in room air for $72 \mathrm{~h}$. Lung lavage was processed as described in "Materials and methods." The SP-A content was calculated as the product of SP-A concentration and lavage or pellet volume. The bars represent the mean \pm 1 SD for the given number of animals in each group. Exposure to $85 \%$ oxygen for $72 \mathrm{~h}$ significantly increased SPA content in all fractions.

oxygen-exposed rat subjected to two-dimensional isoelectric focusing and SDS-PAGE in order to resolve the different isoforms of SP-A. This lavage material contained primarily sialylated forms of SP-A with a charge distribution similar to the forms previously identified in non-oxygen-exposed rats $(20,34)$. The high mannose intracellular storage forms of SP-A were not detected in the lavage fluid of oxygen-exposed or control animals.

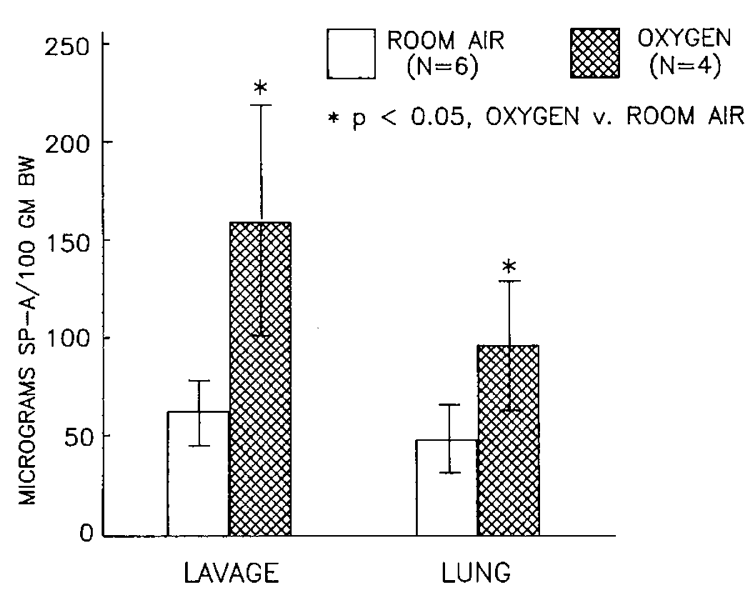

Fig. 3. SP-A content of lavage and lung homogenate. Rats were maintained in either $85 \%$ oxygen or in room air for $72 \mathrm{~h}$. Lung lavage and homogenate were processed as described in "Materials and methods." The SP-A content was calculated as the product of SP-A concentration and lavage or homogenate volume and expressed per $100 \mathrm{~g}$ body weight. The bars represent the mean \pm 1 SD for the number of animals in each group. Exposure to $85 \%$ oxygen for $72 \mathrm{~h}$ significantly increased both lavage and lung SP-A content.

DSPC and total protein were also increased in lavage fluid from oxygen-exposed animals (Fig. 5). Surfactant pellet DSPC was increased approximately 9 -fold in the oxygen-treated animals $(1080 \pm 602$ versus $123 \pm 61 \mu \mathrm{g})$. The surfactant pellet DSPC/ SP-A ratio was also increased by oxygen treatment (10.3 versus $5.35, p<0.05$ ). The total protein in surfactant pellets was increased in the oxygen-exposed rats, although the variance was quite large due to several animals with extremely large amounts of protein in the lavage fluid.

\section{DISCUSSION}

In the present study we found that the amounts of SP-A, total protein, and DSPC recovered in alveolar lavage from adult male rats exposed to $85 \%$ oxygen for $72 \mathrm{~h}$ were significantly increased as compared to rats maintained in room air. Although increases in alveolar total protein and albumin content have been described with pulmonary oxygen injury $(3,6,8)$, this effect of hyperoxic exposure on airway content of SP-A has not been previously reported. This increase in the amount of SP-A recovered in bronchoalveolar lavage was accompanied by a similar increase in lung SP-A content. Thus, hyperoxic exposure caused an overall increase in alveolar and lung SP-A content, and not simply a shift from intracellular to extracellular pools.

SP-A is a glycoprotein synthesized and secreted primarily by pulmonary epithelial cells. It is normally present in the alveolus where it associates with surfactant phospholipids and calcium to form aggregates of tubular myelin $(21,22,35)$. Although SP-A may have a role in lowering alveolar surface tension (19), it also functions as a regulator of surfactant phospholipid metabolism $(15,16,18)$. It is a potent inhibitor of phospholipid secretion from alveolar type II cells $(15,16)$ and stimulates reuptake of surfactant phospholipids into type II cells in vitro $(15,18)$. Thus, an increase in airway content of SP-A after hyperoxic exposure may have important effects on surfactant phospholipid metabolism.

We found a significant increase in the DSPC content of lavage obtained from oxygen-exposed rats. Other investigators also demonstrated similar increases in alveolar phospholipids after hyperoxic exposure. Valimaki et al. (10) demonstrated a $50 \%$ increase in total lipid phosphorus and phosphatidylcholine in alveolar lavage from rats exposed to $100 \%$ oxygen for $66 \mathrm{~h}$. Young et al. (11) demonstrated a 5-fold increase in alveolar DSPC in adult rats exposed to $85 \%$ oxygen for 7 days. Other 
a b $\quad$ c $\quad$ d

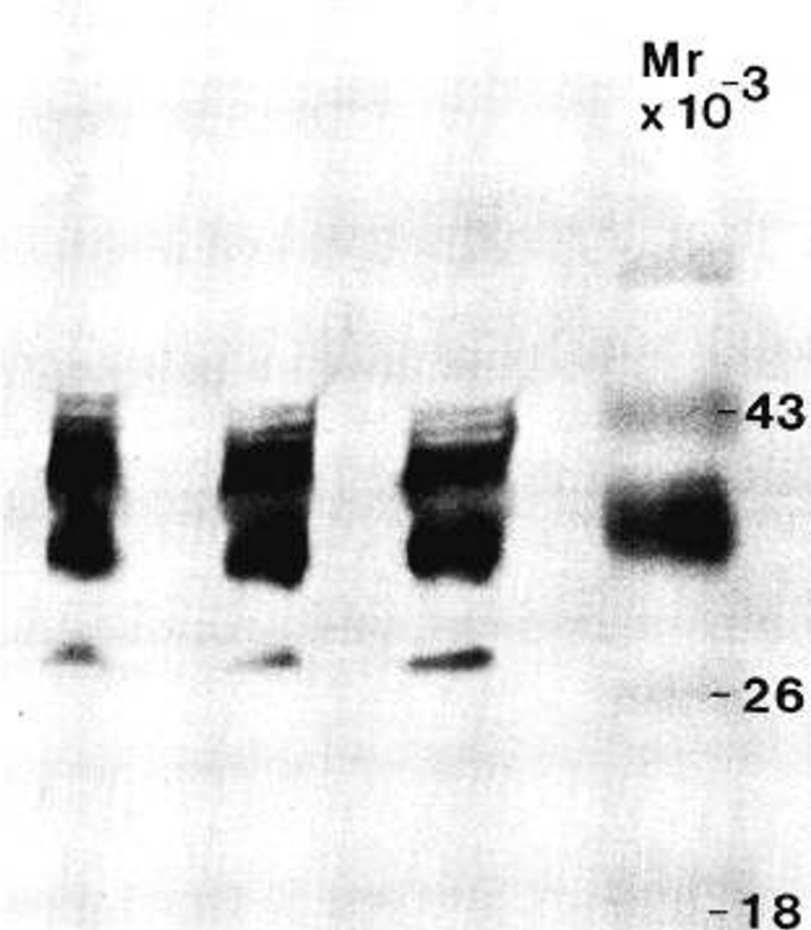

A
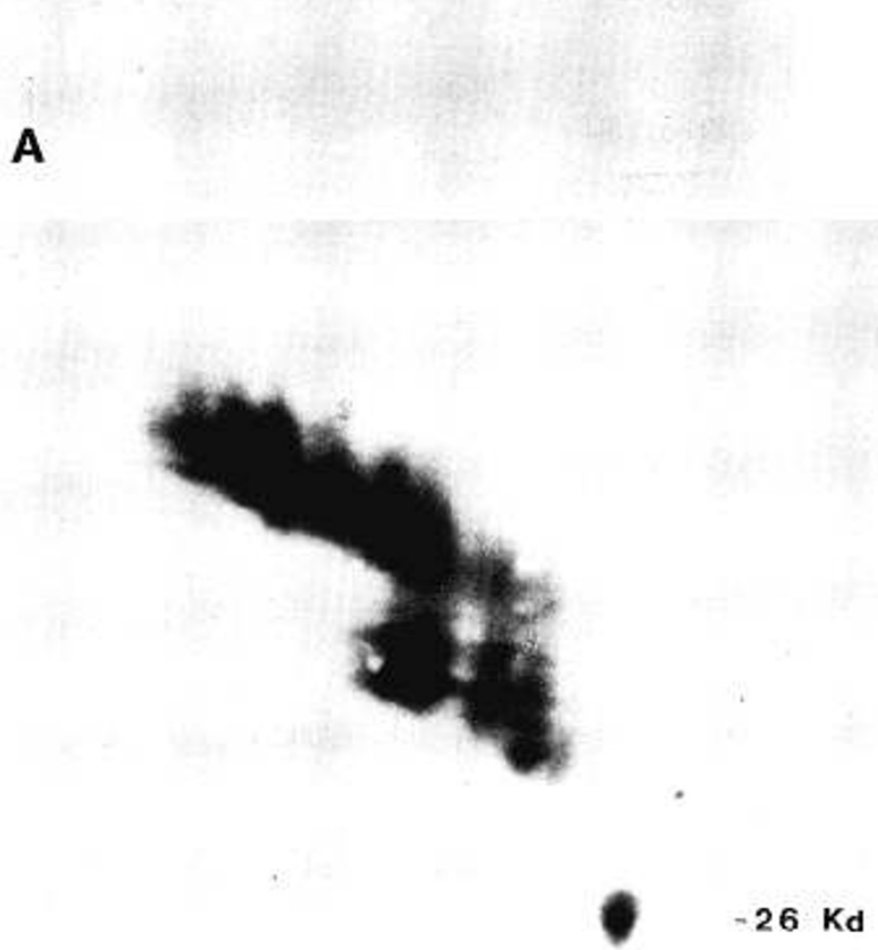
B
4.2
pl
4.8

Fig. 4. Immunoblot analysis of lavage. $A$, approximately $1 \mu \mathrm{g}$ of alveolar lavage SP-A from each of three oxygen exposed rats (lanes $a$ to $c$ ) was analyzed by immunoblot analysis of proteins separated by SDS-PAGE. No proteolytic fragments of SP-A were seen. Lane $d$ contains mol. wt markers. $B$, lavage material containing $150 \mu \mathrm{g}$ of total protein from a rat exposed to $85 \%$ for $72 \mathrm{~h}$ was subjected to two-dimensional IEF-SDSPAGE. Fully sialylated forms of SP-A were present with a charge distribution similar to that seen in lavage from room air animals. High mannose, intracellular forms of SP-A were not detected. 


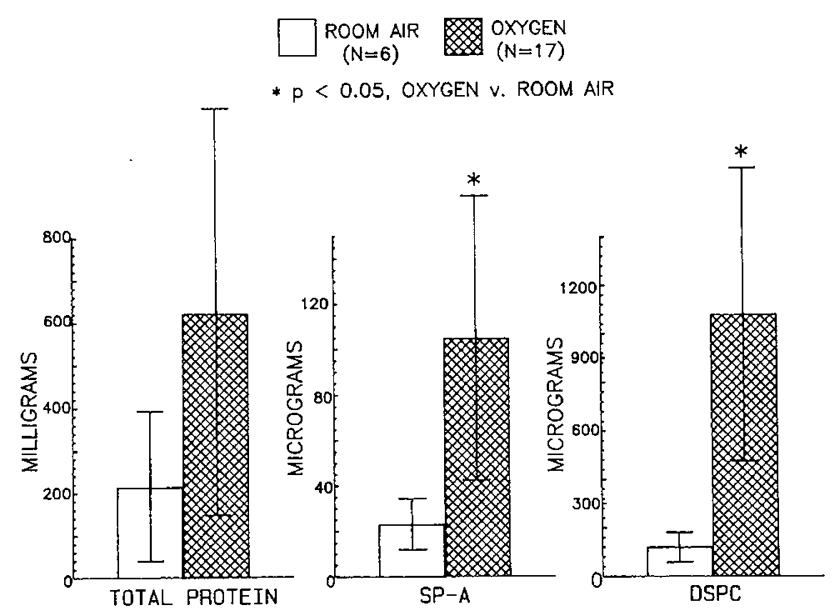

Fig. 5. Total protein, DSPC, and SP-A recovered in the surfactant pellets. Animals were lavaged and the surfactant pellet processed as described in "Materials and methods." Values represent total amounts of protein, SP-A, and DSPC recovered in the surfactant pellets. The bars represent mean $\pm 1 \mathrm{SD}$ for the given number of animals. Exposure to $85 \%$ oxygen for $72 \mathrm{~h}$ significantly increased the amount of SP-A and DSPC present in the surfactant pellets.

investigators found either no change in, or decreased lavage phospholipid content after hyperoxic exposure $(3,4,6-8)$, however, their studies differed with regard to the age and species of the animals studied and the amount and duration of oxygen exposure.

The amount of DSPC recovered in the surfactant pellets from oxygen-exposed rats was increased 8- to 9-fold over the amount recovered from control rats, whereas the amount of SP-A was increased 4- to 5-fold. This disproportionate increase suggests independent regulation of airway surfactant lipid and protein content. There is in vitro evidence that the synthesis of SP-A and surfactant phospholipids may be dissociated. In human fetal lung explants, insulin and cortisol inhibit SP-A synthesis, yet stimulate incorporation of choline into DSPC (36). SP-A is not synthesized in mixed monolayer or organotypic cell cultures prepared from fetal tissues although lamellar bodies containing DSPC are made in these cell systems (37).

To increase the ratio of DSPC to SP-A in the surfactant pellets, oxygen exposure must either increase the total amount of airway DSPC relative to SP-A or increase the amount of DSPC that pelleted relative to SP-A. Hyperoxia may alter the sedimentation of lipid and protein during centrifugation at $12,500 \times \mathrm{g}$, thus altering the lipid and protein composition of the surfactant pellets. We found that oxygen exposure increased the percentage of SP-A that pelleted during centrifugation at $12,500 \times g(29 \pm$ $16 \%$ versus $15 \pm 6 \%$ ). The amount of DSPC in the lavage aliquots from the room air animals was below the limits of detection of our assay, and therefore we were unable to compare the amount of DSPC that sedimented at $12,500 \times g$ in oxygen exposed and room air animals. However, $102 \pm 42 \%$ (mean \pm 1 $\mathrm{SD}, n=6$ ) of the DSPC present in unprocessed lavage from oxygen-exposed animals was recovered in the $12,500 \times g$ pellets. Young et al. (11) reported that approximately $60 \%$ of the total DSPC in lavage from rats exposed to $85 \%$ oxygen for 7 days sedimented at $550 \times g \times 10 \mathrm{~min}$. These are higher percentages than would be expected from other studies on surfactant phospholipid sedimentation from animals not exposed to hyperoxia (38-40). Alveolar surfactant material consists of subfractions that differ in particulate size and density and in lipid and protein composition (38-41). Large multilamellar aggregates of surface active material and tubular myelin are rich in SP-A and sediment at modest gravitational forces. Lighter fractions, consisting primarily of smaller unilamellar vesicles, have less SP-A and do not sediment at high gravitational forces (38-41). These subfractions of alveolar lavage may represent forms of surfactant that differ in surface activity and effects on surfactant phospholipid metabolism (38-42). Our data suggest that the sedimentation characteristics of surfactant phospholipid and protein are altered by hyperoxia. This may reflect changes in the relative amounts and composition of different surfactant subfractions.

Total lung capacity and lung compliance were decreased after exposure to $85 \%$ oxygen for $72 \mathrm{~h}$. This agrees with the findings of other investigators (3-6). The changes seen in hysteresis document that significant pulmonary injury has occurred, but do not necessarily implicate alterations in surfactant. Although this study was not designed to explore possible mechanisms for the decrease in pulmonary compliance, other investigators have suggested that decreased alveolar phospholipid content contributes to decreased pulmonary compliance (3). The finding that oxygen exposure increased alveolar content of both DSPC and SP-A in association with decreased pulmonary compliance, suggests that the changes in pulmonary compliance are not related to quantitative decreases in these two surfactant components. A decrease in the amount of alveolar SP-A would not necessarily be expected to cause a reduction in the surface tension-lowering ability of surfactant. Recent studies show that SP-A has relatively weak biophysical activity when mixed with phospholipids (28, 43) although it may act synergistically with the low mol. wt., hydrophobic surfactant proteins (19).

Impaired surfactant function may contribute to decreased compliance. Holm et al. (16) demonstrated that lavage material from rabbits exposed to $100 \%$ oxygen for $60 \mathrm{~h}$, followed by a 24-h recovery in room air, had severely impaired dynamic surface tension-lowering ability. The animals in our study had significantly increased alveolar protein content, and Notter et al. (44) and others $(45,46)$ showed that several serum proteins inhibit surfactant function when tested in vitro. Other factors, including alterations in tissue compliance, will contribute to the decrease in pulmonary compliance. Beckman and Weiss (3) suggested that both decreased tissue compliance and changes in surface active materials contributed to decreased lung compliance in adult rats exposed to $100 \%$ oxygen for $60-66 \mathrm{~h}$.

The mechanism of the observed increase in alveolar SP-A is unclear. There are several possibilities including increased numbers of type II cells secreting SP-A, leakage of intracellular components from damaged cells, or changes in synthesis or degradation of SP-A. Adult rats exposed to $85 \%$ oxygen for 7 days develop type II cell hyperplasia and have increased lung and lavage DSPC content (11). However, exposure to $85 \%$ oxygen for $72 \mathrm{~h}$ does not significantly increase numbers of type II cells (47). Leakage of intracellular SP-A from damaged type II cells is also possible. However, significant amounts of intracellular SP-A are present as high-mannose intermediate forms (34, 48); and these forms were not detected in lavage material from the rats exposed to hyperoxia in the present study. This suggests that the increased alveolar SP-A content is not derived from damaged type II cells.

Specific increases in SP-A synthesis and secretion in response to hyperoxia would increase alveolar content of SP-A. The increase in alveolar SP-A content was accompanied by an increase in lung tissue SP-A content, which implies that the increased alveolar SP-A content is not due solely to increased secretion of intracellular stores of SP-A, but may be accompanied by increased SP-A production. Direct effects of hyperoxia on SPA synthesis have not been reported. Gacad and Massaro (5) demonstrated decreased total protein synthesis in lung slices prepared from rats exposed to $98 \%$ oxygen for $24 \mathrm{~h}$. The synthesis of the protein components of surface active material extracted from the slices was decreased, but the authors did not identify the specific proteins involved (5). Alterations in surfactant metabolism would also increase alveolar DSPC and SP-A content. Surfactant phospholipids are taken up by type II cells and undergo recycling $(49,50)$. Impaired reuptake of surfactant phospholipids would increase alveolar DSPC content. How SP- 
$A$ is cleared from the airway is unknown, however, it is found in alveolar macrophages (51), and smaller proteins that may be proteolytic fragments of SP-A are found in alveolar lavage fluid (52). In this study SP-A was increased 2- to 3-fold in both unprocessed lavage from oxygen exposed animals as well as in a cell free supernatant of lavage, and we were unable to detect proteolytic fragments of SP-A in lavage material. Thus, the increase in SP-A is intact protein.

In summary, exposure to $85 \%$ oxygen for $72 \mathrm{~h}$ decreased lung capacity and compliance and increased airway levels of DSPC and SP-A and tissue levels of SP-A in adult male rats. Because SP-A is important in the regulation of surfactant metabolism, this finding is potentially important in the pathophysiology of RDS and in understanding pulmonary oxygen injury in newborns. Further studies are needed to elucidate the mechanisms that account for the increase in airway surfactant components during oxygen exposure.

Acknowledgments. The authors acknowledge the technical assistance of William Hall, Michael Burhans, Charles Hall, and Robert Johnson, and thank Jeffrey B. Whitsett, M.D. for his many helpful discussions.

\section{REFERENCES}

1. Deneke SM, Fanburg BL 1980 Normobaric oxygen toxicity of the lung. N Engl J Med 303:76-86

2. Frank L, Massaro D 1980 Oxygen Toxicity. Am J Med 69:117-126

3. Beckman DL, Weiss HS 1969 Hyperoxia compared to surfactant washout on pulmonary compliance in rats. J Appl Physiol 26:700-779

4. Redding RA, Arai T, Douglas WH, Tsurutani H, Overs J 1975 Early changes in lungs of rats exposed to $70 \%$ oxygen. J Appl Physiol 38:136-142

5. Gacad A, Massaro D 1973 Hyperoxia: influence on lung mechanics and protein synthesis. J Clin Invest 52:559-565

6. Holm BA, Notter RH, Siegle J, Matalon S 1985 Pulmonary physiological and surfactant changes during injury and recovery from hyperoxia. J Appl Physiol 59:1402-1409

7. Barckow D, Kynast G, Schirop T 1981 Changes of the lecithin content in the rat lung under the influence of toxic doses of hypnotics and nonphysiological oxygen concentrations. Prog Respir Res 15:113-120

8. Brashear RE, Christian JC 1973 Endobronchial lavage phospholipids and protein in rats protected from oxygen toxicity by hypoxia pretreatment. Metabolism 22:1345-1348

9. Giammona ST, Kerner D, Bondurant S 1965 Effect of oxygen breathing at atmospheric pressure on pulmonary surfactant. J Appl Physiol 20:855-858

10. Valimaki M, Pelliniemi T, Niinikoski J 1975 Oxygen-induced changes in pulmonary phospholipids in the rat. J Appl Physiol 39:780-787

11. Young SL, Crapo JD, Kremers SA, Brumley GW 1982 Pulmonary surfactant lipid production in oxygen-exposed rat lungs. Lab Invest 46:570-576

12. Gross NJ, Smith DM 1981 Impaired surfactant phospholipid metabolism in hyperoxic mouse lungs. J Appl Physiol 51:1198-1203

13. Ward JA, Roberts RJ 1984 Hyperoxia effects on pulmonary pressure: volume characteristic and lavage surfactant phospholipid in the newborn rabbit. Biol Neonate 46:139-148

14. Ward JA, Roberts RJ 1984 Effect of hyperoxia on phosphatidylcholine synthesis, secretion, uptake, and stability in the newborn rabbit lung. Biochim Biophys Acta 796:42-50

15. Rice WR, Ross GF, Singelton FM, Dingle S, Whitsett JA 1987 Surfactantassociated protein (SAP-35) inhibits surfactant phospholipid secretion from pulmonary type II epithelial cells. J Appl Physiol 63:692-698

16. Dobbs LG, Wright JR, Hagwood S, Gonzalez R, Venstrom $K$, Nellenbogen J 1987 Pulmonary surfactant and its components inhibit secretion of phosphatidylcholine from cultured rat alveolar type II cells. Proc Natl Acad Sci USA 84:1010-1014

17. Whitsett JA, Ohning BL, Ross GF, Meuth J, Weaver TE, Holm BA, Shapiro DL, Walker BH 1986 Hydrophobic surfactant associated protein in whole lung surfactant and its importance for biophysical activity in lung surfactant extracts used for replacement therapy. Pediatr Res 20:460-467

18. Wright JR, Wager BE, Hagwood S, Dobbs L, Clements JA 1987 Surfactant apoprotein $\mathrm{Mr}=26,000-36,000$ enhances uptake of liposomes by Type II cells. J Biol Chem 262:2888-2894

19. Hawgood S, Benson BJ, Schilling J, Damm D, Clements JA, White BT 1987 Nucleotide and amino acid sequences of pulmonary surfactant protein SP18 and evidence for cooperation between SP-18 and SP-28-36 in surfactant lipid absorption. Proc Natl Acad Sci USA 84:66-70

20. Whitsett JA, Weaver TE, Hull W, Ross G, Dion C 1985 Synthesis of surfactantassociated glycoprotein A by rat type II epithelial cells. Primary translation products and post-translational modification. Biochim Biophys Acta 828:162-171

21. Williams MC, Benson BJ 1981 Immunocytochemical localization and identi- fication of the major surfactant protein in adult rat lung. $J$ Histochem Cytochem 29:291-305

22. Balis JU, Patterson JF, Paciga JE, Haller EM, Shelley SH 1985 Distribution and subcellular localization of surfactant-associated glycoproteins in human lung. Lab Invest 52:657-669

23. Kikkawa IY, Smith F 1983 Cellular and biochemical aspects of pulmonary surfactant in health and disease. Lab Invest 49:122-139

24. Katyal SL, Singh G 1983 An enzyme-linked immunoassay of surfactant apoproteins. Its application to the study of fetal lung development in the rat. Pediatr Res 17:439-443

25. McMahan M, Mimouni F, Miodovnik M, Hull W, Whitsett JA 1987 Surfactan associated protein (SAP-35) in amniotic fluid from diabetic and non-diabetic pregnancies. Obstet Gynecol 70:94-98

26. Lees MB, and Paxman S 1972 Modification of the Lowry procedure for the analysis of proteolipid proteins. Anal Biochem 47:184-192

27. Morrissey JH 1981 Silver stain for proteins in polyacrylamide gels: a modified procedure with enhanced uniform sensitivity. Anal Biochem 117:307-310

28. Ross GF, Notter RH, Meuth J, Whitsett JA 1986 Phospholipid binding and biophysical activity of pulmonary surfactant-associated protein (SAP)-35 and its non-collagenous COOH-terminal domains. J Biol Chem 261:1428314291

29. Laemmli UK 1970 Cleavage of structural proteins during the assembly of the head of bacteriophage $T_{4}$. Nature 227:680-685

30. Garrison JC, Wagner JD 1982 Glucagon and the $\mathrm{Ca}^{2+}$-linked hormone angiotensin II, norepinephrine, and vasopressin stimulate the phosphorylation of distinct substrates in intact hepatocytes. J Biol Chem 257:13135-13143

31. Whitsett JA, Hull W, Ross G, Weaver T 1985 Characteristics of human surfactant-associated glycoprotein(s). A. Pediatr Res 19:501-508

32. Johnson DA, Gautsch JW, Sportsman JR, Elder JH 1984 Improved technique utilizing non-fat dry milk for analysis of proteins and nucleic acids transferred to nitrocellulose. Gene Anal Technol 1:3-8

33. Mason J, Nellenbogen J, Clements JA 1976 Isolation of disaturated phosphatidylcholine with osmium tetroxide. J Lipid Res 17:281-284

34. Whitsett JA, Ross G, Weaver T, Rice W, Dion C, Hull W 1985 Glycosylation and secretion of surfactant associated glycoprotein-A. J Biol Chem 260:15273-15279

35. Hawgood S, Benson BJ, Hamilton RL 1985 Effects of a surfactant-associated protein and calcium ions on the structure and surface activity of lung surfactant lipids. Biochemistry 24:184-190

36. Snyder JM, Mendelson CR 1987 Insulin inhibits the accumulation of the major lung surfactant apoprotein in human fetal lung explants maintained in vitro. Endocrinology 120:1250-1257

37. Weaver TE, Ross G, Daugherty C, Whitsett JA 1986 Synthesis of surfactantassociated protein, 35,000 daltons, in fetal lung. J Appl Physiol 61:694-700

38. Magoon MW, Wright JR, Baritussio A, Williams MC, Goerke J, Benson BJ, Hamilton RL, Clements JA 1983 Subfractionation of lung surfactant: implications for metabolism and surface activity. Biochim Biophys Acta 750:18-31

39. Spain CL, Silbajoris R, Young SL 1987 Alterations of surfactant pools in fetal and newborn rat lungs. Pediatr Res 21:5-9

40. Thet LA, Clerch L, Massaro GD, Massaro D 1979 Changes in sedimentation of surfactant in ventilated excised rat lungs. Physical alterations in surfactant associated with the development and reversal of atelectasis. J Clin Invest 64:600-608

41. Wright JR, Benson BJ, Williams MC, Goerke J, Clements JA 1984 Protein composition of rabbit alveolar surfactant subfractions. Biochim Biophys Acta 791:320-332

42. Wright JR, Wager RE, Hamilton RL, Huang M, Clements JA 1986 Uptake of lung surfactant subfractions into lamellar bodies of adult rabbit lungs. $J$ Appl Physiol 60:817-829

43. Notter RH, Shapiro DL, Ohning B, Whitsett JA 1987 Biophysical activity of synthetic phospholipids combined with purified lung surfactant 6000 Dalton apoprotein. Chem Phys Lipids 44:1-17

44. Holm BA, Notter RH, Finkelstein JN 1985 Surface property changes from interactions of albumin with natural lung surfactant and extracted lung lipids. Chem Phys Lipid 38:287-298

45. Fuchimukai T, Fujiwara T, Takahashi A, Enhorning G 1987 Artificial pulmonary surfactant inhibited by proteins. J Appl Physiol 62:429-437

46. Ikegami M, Jobe A, Jacobs H, Lam R 1984 A protein from airways of premature lambs that inhibits surfactant function. J Apply Physiol 57:11341142

47. Crapo JD, Barry BE, Foscue HA, Shelburne J 1980 Structural and biochemical changes in rat lungs occurring during exposures to lethal and adaptive doses of oxygen. Am Rev Respir Dis 122:123-143

48. O'Reilly MA, Nogee L, Whitsett JA 1988 Requirement of the collagenous domain for carbohydrate processing and secretion of a surfactant protein SP-A. Biochim Biophys Acta 969:176-184

49. Fisher AB, Dodia D, Chander A 1987 Degradation and reutilization of alveolar phosphatidylcholine by rat lungs. J Appl Physiol 62:2295-2299

50. Jacobs H, Jobe A, Ikegami M, Conaway D 1983 The significance of reutilization of surfactant phosphatidylcholine. J Biol Chem 258:4159-4165

51. Walker SR, Williams MC, Benson B 1986 Immunocytochemical localization of the major surfactant apoproteins in type II cells, clara cells, and alveolar macrophages of rat lung. J Histochem Cytochem 34:1137-1148

52. King RJ, Martin H, Mitts D, Holmstrom FM 1977 Metabolism of the apoproteins in pulmonary surfactant. J Appl Physiol 42:485-491 